\title{
"Contando os Plaquê de 100": o significado da ostentação para além do Funk
}

\section{"Contando os Plaquê de 100": the Meaning of Ostentation Beyond Funk}

\author{
LUIS FERNANDO MOREIRA DA SILVA* \\ NATACHA SECCO SANTOS** \\ MARCIO PASCOAL CASSANDRE***
}

\section{RESUMO}

A palavra ostentação tem sido usada em diversos meios de comunicação. Esse termo ganhou força com o surgimento do funk ostentação, portador de letras que remetem ao consumo. Ele e suas variáveis, como: ostensível, ostensivo e ostentar têm no senso comum diversos significados, como sucesso, posse de bens materiais e evidenciar o que se tem. Este artigo, a partir de análises bibliográficas e bibliométricas, tem como objetivo lançar luz ao tema, buscando sua construção ao longo do tempo em diversas áreas do conhecimento, a fim de produzir um entendimento mais amplo do que essa palavra representa. Para tanto, os resultados da pesquisa sugerem que existem aspectos profundos no ato de comprar, sendo o desejo, as modas e a vontade de possuir bens e objetos que causem boa impressão ou status, alguns desses fatores. A ostentação está aglutinada ao querer, e com ela a necessidade de mostrar, portanto, não basta possuir, é preciso que a posse seja ostensível.

Palavras-chave: Ostentação. Relações de poder. Consumo.

* Universidade Estadual de Maringá. Mestrando no Programa de Pós Graduação em Administração da Universidade Estadual de Maringá. luisfmsmoreira@gmail.com

** Universidade Estadual de Maringá. natacha.secco@agenciaeuphoria.com.br

*** Universidade Estadual de Maringá. mcassandre@hotmail.com 


\section{Abstract}

The word ostentation has been used in various forms of communication. This term gained strength with the appearance of funk ostentation, bearer of letters that refer to consumption. This term and its variables, such as: ostensible, ostentatious and ostensive without different meanings, such as success, goods assets, possession of material goods evidence what you have. This article, based on bibliographical and bibliometric analyzes, aims to shed light on the theme, seeking its construction over time in several areas of knowledge, in order to produce a broader understanding than this representative word. For both, how the modes, and the will to possess goods and objects that cause good impression or status some of the factors. Ostentation is agglutinated when wanting, and with it is a need to show, therefore, not enough possess, it must be an ostensible possessor.

Keywords: Ostentation. Power Relations. Consumption.

\section{INTRODUÇÃo}

A palavra ostentação no dicionário Michaelis Online significa: "Ato ou efeito de ostentar; Ato de fazer alarde de si mesmo ou de algo que é seu; Exibição de luxo, poder ou riqueza" (OSTENTAÇÃO, 2018). Essa palavra tem sido utilizada para definir uma nova modalidade de funk, nem sempre evidenciando o termo em si, mas trazendo a temática de mostrar o que é luxuoso. "Plaque de 100" música de Mc Guime (2012), cujo nome também inspirou o título desse artigo é uma das músicas do gênero funk ostentação mais ouvidas no canal do cantor no youtube. Além dela, existem outras tão famosas quanto, tais como: "Bonde da Juju”, “Ta Patrão" e "Como é bom ser vida loka". A incidência dessa palavra nas letras de músicas, no vocabulário cotidiano das pessoas e na mídia são os motivos que despertaram o interesse dos autores desse trabalho.

O surgimento do funk ostentação está atrelado ao aumento das possibilidades de consumo das classes C, D e E, ou seja, de camadas cujo poder aquisitivo fora sempre baixo. $\mathrm{O}$ aumento do consumo nessas camadas sociais ocorreu a partir dos anos 2000 devido ao cenário econômico nacional, o acesso à informação e a facilitação do crédito (NARDI, 2009). Bens de consumo que antes pareciam estar distantes da realidade de pessoas pertencentes à essas classes 
econômicas, tornaram-se mais viáveis fazendo aumentar o desejo pelo consumo de marcas.

Segundo Dantas et al (2018) o funk ostentação estabelece uma relação entre marcas e o consumo adolescente. Pelo conteúdo das letras pode-se perceber quais marcas são mais desejadas, há ligação psicológica entre as facilidades trazidas pelo uso das marcas, dentre elas a possibilidade de sucesso amoroso, já que um rapaz com dinheiro e a posse de marcas desejadas também teria mulheres à sua disposição.

No entanto, limitar as possibilidades teóricas do funk ostentação para o público adolescente pode nos levar a interpretar que a ostentação está segmentada apenas a adolescentes das classes C, D e E. Considera-se que a ostentação permeia outros ambientes, inclusive o organizacional, quando nos ambientes de trabalhos as profissões e os cargos acabam por trazer notoeriedade para aqueles que os ocupam.

Tenta-se, neste trabalho, significar a palavra ostentação próxima à categoria teórica de 'poder' na área dos estudos organizacionais. O poder é afeto ao cargo ocupado dentro de uma hierarquia organizacional, haja vista que algumas profissões ostentam um status superior pelos salários associados a elas, pelo modo de se vestirem, pelo título que a profissão lhe empresta, pelas vantagens em relação aos outros profissionais, entre outros aspectos.

De outra forma, a relação poder-ostentação pode ser decorrente das prerrogativas que o cargo atribui ao sujeito, mesmo possuindo baixa formação escolar, mas que lhe dá o direito de utilizar um espaço físico diferenciado, o carro da instituição, um carimbo contendo o seu cargo de destaque ou outro símbolo ou signo representativo. A visão de ostentação apresentada neste artigo refere-se à apropriação de algo para que se tenha projeção no meio em que alguém exerce uma prática laboral.

Para a formação do conceito de "ostentação" foram usadas as palavras-chave poder, artefato social, cultura, funk ostentação e consumo. Em um primeiro momento do trabalho, buscou-se levantar referências bibliográficas por meio de fichamento de artigos científicos em bases científicas, caracterizando o trabalho como uma pesquisa exploratória, a partir de dados secundários, de uso das pesquisas 
do tipo bibliográfica e bibliométrica. Para tanto, estabeleceu-se 'ostentação' como categoria teórica análoga, ou seja, que se assemelha a categoria poder, de forma que os diversos conceitos relacionados à ostentação fossem levantados para possibilitar a construção mais aprofundada do seu conteúdo, dado que o termo é bastante amplo, possibilitando seu uso para diversos fins. Nesse artigo, a busca do significado do termo cinge o conceito de poder.

A partir da conclusão dos fichamentos, no segundo momento da pesquisa aqui trazida, um debate sobre o significado do termo "ostentação" é sugerido, por meio de seu entendimento em áreas do conhecimento, tais como: Ciências Políticas, Pedagogia, Comunicação Social, Turismo, Engenharia de Produção e Administração.

Este trabalho está dividido em cinco partes além desta introdução. A segunda apresenta a metodologia empregada. A terceira dedica-se a revisar teoricamente as bibliografias encontradas. A quarta apresenta os resultados finais da pesquisa de forma a sugerir um conceito para o termo ostentação. Por fim, a quinta a apresenta algumas ideias advindas dessa nova classificação por meio das considerações finais do artigo.

\section{Metodologia}

Este artigo é caracterizado como uma pesquisa exploratória a partir de dados secundários por meio de pesquisas do tipo bibliográfica e bibliométrica. Conforme Jung (2004, p. 160), o estudo bibliográfico objetiva "conhecer as diversas formas de contribuições científicas existentes que foram realizadas sobre determinado assunto ou fenômeno".

Para Cruz e Ribeiro (2003, p. 12), um estudo bibliográfico "pode visar um elemento dos trabalhos realizados anteriormente sobre o mesmo tema estudado no momento, pode identificar e selecionar os métodos e técnicas a serem utilizados, além de fornecer subsídios" para a pesquisa (CRUZ; RIBEIRO, 2003).

Com base nos autores mencionados, essa pesquisa revisou os anais dos eventos científicos vinculados à ANPAD (Associação Nacional de Pós-Graduação e Pesquisa em Administração) e os artigos publicados em periódicos, por meio da ferramenta de pesquisa disponível no site do SPELL (www.spell.org.br), no período entre 
2000 e 2015. A opção por realizar a pesquisa nos artigos publicados nos anais do EnANPAD ocorreu pelo fato de esse encontro, segundo Bignetti e Paiva (2001), reunir anualmente muitos dos principais pesquisadores de Administração, principalmente os vinculados a programas de pós-graduação e, de acordo com Vergara e Pinto (2000), representar um espaço que fornece a oportunidade para autores de diferentes instituições divulgarem suas pesquisas.

Escolheu-se iniciar o levantamento pelo ano 2000 devido o surgimento do funk ostentação se dar posterior à ampliação do consumo de marcas pela classe C, D e E, como explicado na introdução. Além disso, as primeiras músicas sobre a temática que se tornaram nacionalmente famosas foram lançadas durante esse período. As palavras-chave pesquisadas foram poder, artefato social, cultura, funk ostentação e consumo. Embora a pesquisa fora realizada em eventos da Administração, a base de dados pesquisada é composta de artigos de áreas afins à administração, por isso é possível encontrar artigos de diversas áreas.

Nesse sentido, acredita-se que os eventos da ANPAD e as publicações disponíveis no SPELL sejam importantes fontes de estudos de diferentes autores sobre ostentação, proporcionando um campo amplo de análise sobre pesquisas vinculadas a essa temática. Como procedimento de pesquisa, selecionou-se os textos por meio eletrônico, revisando a utilização nos títulos, nas palavras-chave e no resumo expressões que indicassem a existência da aplicação empírica ou discussão teórica sobre ostentação e poder, visto que, para esse artigo, ostentação pode ser considerada uma categoria análoga a poder.

Para organização dos dados uma tabela foi contruída; nela estão presentes as principais informações para caracterização dos artigos. São elas: título, autor, ano, área periódico, termo investigado e conceito chave. Após construção da tabela partiu-se para uma segunda leitura dos textos com finalidade de selecionar conceitos capazes de oferecer sustentação teórica à construção deste artigo.

\section{SignifiCANdo A OSTENTAÇão}

Ostentação é um termo que comumente se escuta em novelas, músicas, programas de televisão. Entre jovens e adolescentes osten- 
tação é uma gíria que, neste caso, significa sucesso. Aquele que está ostentando tem consigo características ou habilidades distintivas, que, pelo senso comum, estão ligadas à posse de bens de consumo ou dinheiro. Contudo, considera-se a possível existência de outros significados além da previsibilidade que a palavra carrega. Dessa forma, uma análise mais aprofundada da ostentação pode trazer reflexões sobre o momento histórico, social, político e cultural desta expressão. Por isso, este capítulo objetiva apresentar aspectos teóricos que ajudem a definir um conceito sobre ostentação.

O artigo "Religião e Poder: Os símbolos do poder sagrado" apresenta a ideia de poder simbólico, ou seja, segundo Pierre Bourdieu (1998 apud PEREIRA, 2008) é o poder que deriva da crença, que só existe porque alguém nele acreditou. Pode-se dizer que, segundo o autor do trabalho, Pereira (2008), essa espécie de poder está coligada a outros tipos de poderes, e que esse poder atribui a símbolos, outrora comuns, significados especiais. Desse modo, assim como na religião, vestimentas, palavras, posturas e ritos determinam hierarquia e a autoridade de todos dentro da empresa. Formal ou informalmente se espera que os chefes trabalhem com determinada roupa e os funcionários com outras, onde cada indíviduo estaciona o automóvel, o tamanho das salas, o conforto das cadeiras, os prêmios que cada um ganhou, são objetivos simbolicamente carregados, cujo significado é conhecido pelo coletivo de pessoas que ali estão.

O poder está diretamente relacionado às organizações, pois os indivídos que delas fazem parte, por meio de suas relações, buscam experimentar seções de controle, visibilidade e reconhecimento. $\mathrm{Na}$ medida em que esses locais de poder são vivenciados, a satisfação no trabalho se amplia. Deter poder é antes de tudo uma necessidade social do sujeito conforme Pereira (2008). Nesse sentido, o poder passa a ser protagonista dentro das organizações, podendo se dar por reconhecimento do grupo no qual está inserido ou por delegação de autoridade (imposição). Esse último sentido é evidenciado por Merton (1978 apud PEREIRA, 2008) como sendo inerente ao cargo e não à pessoa que o ocupa.

Enriquez (1997) define as organizações como espaços em que relações de poder e controle são desenvolvidas, haja vista que as organizações são compreendidas como um sistema cultural, sim- 
bólico e imaginário, que passa a ter ferramentas que objetivam a modelagem dos pensamentos e a indução de comportamentos indispensáveis à sua dinâmica.

A relação do sujeito, seu corpo e poder, são simbólicas e representativas, não podendo dissociá-las. Se o sujeito busca poder, ele poderia fazê-lo pela composição social que o leva a se satisfazer nesta situação? Ele o faz pelo seu corpo, por meio do trabalho e de sua produção social? Seria o corpo a tela desses artistas sociais, em que as obras primas de suas vidas são ostentadas? Pode se entender que o corpo é o lugar privilegiado de investimentos, conformação dos gestos e dos comportamentos (GONÇALVES, 1998).

Para Galbraith (1989) o poder é o produto de um continuum, que parte da persuasão objetiva, visível, até o ponto em que aquilo que o indivíduo, no seu contexto social, fora levado acreditar, seja intrinsecamente correto. Por isso entende-se que os corpos colaboram para que haja certa distinção objetiva entre os sujeitos, nele se impregnam os símbolos e os artefatos sociais afirmando sua posição nas sociedades, seja ela qual for.

O artigo "Discurso organizacional como manifestação do poder: um estudo com executivos de empresas modernas" (PABST; SIQUEIRA, 2008) mostra a composição do discurso empresarial e sua função social como uma espécie de artefato social quando demostra que a materialidade das falas de executivos modernos corresponde ao modus próprio, possuindo características inclusive simbólicas. Artefato social é todo o objeto que se reveste de um determinado significado. Aventais, copos, cadeiras, uniformes e até mesmo a fala são caracterizados como artefatos sociais. Esses artefatos estão à volta dos indivíduos, estão em seus corpos propriamente, se não alocados nele, ao redor dele. O corpo funciona como um campo de materialização do simbólico quando veste, consome, usa. Sendo assim, poderia-se dizer que a corporeidade é um requisito importante para o ato de ostentar.

O trabalho "Relações de poder: uma abordagem voltada à cultura organizacional" (ZAPPANI et al., 2009) exibe a caracterização dos corpos nas organizações de modo simbólico quando, ao confrontar poder e cultura organizacional em cinco empresas brasileiras, apresenta que essa relação "poder" versus "cultura" produz modos 
de se comportar, de agir, de vestir e de falar que são diferenciados em cada uma dessas empresas. Ou seja, cada organização, entidade ou grupo ao relacionar-se entre seus membros, poderá se apoiar em artefatos sociais cuja função é ajudar na coesão simbólica da expressão desses grupos.

De acordo com Morgan (1996), as organizações são um fenômeno cultural e modificam-se em função das alterações do ambiente em que estão inseridas, ou seja, as organizações nascem e se constituem a partir de necessidades e características do ambiente de sua inserção. Todo o conjunto de tradições, costumes, hábitos e rotinas forma um arcabouço simbólico ao qual o ser humano está sempre recorrendo para entender sua vivência (ZAPPANI et al., 2009).

Zappani et al (2009) apontam que Motta (2001), entende a existência de variáveis culturais desenvolvidas ao longo do tempo que fornecem um sentido comum aos indívudos que convivem em uma determinada organização, voltadas para a convergência de objetivos sujeito/organização. Caso contrário, existirá uma incongruência nos objetivos organizacionais e individuais. $\mathrm{O}$ termo ostentação deve ser observado a partir dessa análise, não como uma palavra somente, mas como o signo que carrega diversas variáveis, e que representa um sentido pelo qual o indivíduo se comunica.

Com a evolução das sociedades e o desenvolvimento de práticas organizacionais, novas formas de interpretação das individualidades surgiram, e com elas, novos meios de gestão e variáveis culturais que foram criadas no percurso histórico (ZAPPANI et al., 2009).

Segundo Zappani et al. (2009) Schein (1992, p. 26) entende cultura como "o conjunto de pressupostos básicos que um determinado grupo inventou, descobriu ou desenvolveu ao aprender a lidar com os problemas de adaptação externa e de integração interna". Sendo assim, a cultura organizacional é a responsável pelo senso de tornar comum, de mostrar àquele que pertence a organização sua forma de agir, de experimentar em meio ao seu contexto. Segundo Aktouf (1994), a cultura é algo muito vasto e muito importante, inscrita muito profundamente nas estruturas sociais, na história, no inconsciente, na experiência vivida e no vir a ser coletivo humano.

Esse conjunto amplo de pressupostos forma, em síntese, camadas mais superficiais, porém existem ainda camadas mais profundas 
capazes de construir a realidade objetiva, neste caso, valores, crenças, ritos, tabús, mitos, normas e a comunicação formal e informal da empresa (ZAPPANI et al., 2009) que acabam condicionando o comportamento das pessoas, que, por sua vez, irão direcionar o comportamento das organizações.

Schein (1992, p. 26) complementa sobre cultura: "a essência da cultura está nas premissas básicas e, uma vez entendido esse nível, os outros níveis superficiais são facilmente entendidos e condizem com elas". Fleury $(1989$, p. 22) comenta que a cultura organizacional promulga "um conjunto de valores e pressupostos básicos expressos em elementos simbólicos, que em sua capacidade de ordenar, atribuir significações, construir a identidade organizacional, tanto agem como elemento de comunicação e consenso, como ocultam e instrumentalizam as relações de dominação".

O artigo "Relações de Poder e Decisão: Conflitos entre médicos e administradores hospitalares" ajuda no entendimento do que são relações de dominação (FERREIRA et al, 2010), que nesse artigo são caracterizadas como "relações de poder", deixam de ser vistas como conceitos finais em si para demonstrar que são produto da relação entre indivíduos. Dessas relações nasce o que se denominado poder. A lógica não está em determinar quem o detém, mas como ele é produzido. Para Ferreira et al (2010) componentes geográficos, sociais e, principalmente da dominação de certos conhecimentos geram estas relações.

As relações de poder e sua ligação com dominação de conhecimentos tornam-se explicitas por meio do artigo "Estudo Observacional das Relações de Poder no Filme: O Óleo de Lorenzo", (MATOS; LIMA e GIESBRECHT, 2011). Os autores apresentam a visão do poder como um monopolizador da verdade; aqueles que detêm, o fazem porque apenas eles possuem as características para tanto. Isso gera indivíduos poderosos, que cada vez mais terão por ação dominar esses artifícios. Essa relação é importante para entender que nem todos alcançarão o poder que desejam, mas, de modo geral, parece que nessa compreensão sempre haverá um indivíduo ideal que galgou patamares maiores e, por isso, tem para si parcela significativa de poder e apreço. 
No artigo "Microfísica do poder no turismo: reflexões sobre as relações de poder no Conselho Estadual de Turismo do Rio Grande do Norte", Virgílio et al (2011), apoiados pelo pensamento de Foucault, produzem uma análise completa sobre as relações de poder no conselho formado por técnicos e representantes da população. Indivíduos buscam deter poder, mesmo que políticas sejam estabelecidas para a descentralização. Isso porque o indivíduo inserido no contexto social brasileiro, construído a partir da cultura e do coletivo de cidadãos, não está acostumado ao protagonismo, mas a uma estrutura de mando e subordinação que tem suas bases ainda no período militar brasileiro. Caracterizando o poder simbólico de modo relacional, esse trabalho buscou definir cultura e cultura organizacional, isso porque evidencia-se que o sujeito se relaciona com os demais membros de seu coletivo a partir da interface cultural gerada historicamente e em seu meio. Sendo assim, a ostentação também é relacional. Pode-se dizer que o que se deseja ostentar está revestido de poder simbólico. Ainda que o discurso seja de descentralização e autonomia verifica-se que os sujeitos querem centralizar-se nos sistemas de crenças coletivas como referência de sucesso.

O texto "Poder e Trabalho: Prazer ou sofrimento" (OLIVEIRA e GARCIA, 2011) busca relacionar poder a prazer e sofrimento. Para os autores, em qualquer organização, influenciadores externos e internos desequilibram a relação entre poder, prazer e sofrimento, gerando pressão. O poder é buscado como uma forma de ampliar o prazer advindo socialmente e financeiramente, contudo, com ele, situações estafantes também se tornam mais presentes no cotidiano dos indivíduos. O poder, então, tem sua ligação fixada com a possibilidade de gerar prazer e sofrimento.

Com o artigo “Ostentação Fora do Normal. 'Quem Tem Motor Faz Amor, Quem Não Tem Passa Mal: Uma análise sobre o Funk da Ostentação'" (SANTOS e PAIVA, 2014) pode-se começar a pensar a ligação entre o estilo musical funk ostentação com os conceitos de poder simbólico relacional, artefatos sociais e distinção trazidos anteriormente. $\mathrm{O}$ artigo apresenta a nova modalidade de funk a partir de uma perspectiva da área de comunicação social, fazendo relação com o consumo, a satisfação e a percepção social pela capacidade de consumir. 
Poderia o funk não ser visto apenas como um estilo musical? Poderia ele como música ou como representação da sociedade ampliar-se para além das comunidades, localidades onde o rítimo nasceu? Talvez não fosse exagero corroborar que sim. Em suma, é na música que detalhes sociais, muitas vezes diáfanos, podem ser vistos em detalhes. O conceito de "cena" é importante para se entender a significação do "funk", pois segundo Essinger (2005), é o ambiente local ou global, marcado pelo compartilhamento de referências estéticos-comportamentais, que supõe o processamento dessas referências em um ou mais gêneros musicais.

Santos e Paiva (2014) afirmam que a cena do funk não está presa à periferia. Está, na verdade, presente em muitos outros ambientes, em festas particulares ou comerciais, sendo natural sua reprodução em diversos ambientes festivos juvenis.

Se o estilo é tão presente no dia a dia de jovens brasileiros, poderia se dizer que se tornou traço da cultura recente do brasileiro jovem, haja vista que o 'Funk ostentação' extrapolou seu local de nascimento, ou seja as comunidades periféricas do Rio de Janeiro e São Paulo, infiltrando-se em muitos outros locais? A ostentação passou a adjetivar o sujeito que detém recursos, dessa forma, a "ostentação" poderia se manifestar de outros modos em nossa sociedade? Poderia ser um traço de nossa cultura ou mesmo estar presente no ambiente empresarial? Indica-se que sim. O entendimento que se pode ter sobre o que é ostentação pode variar de acordo com a cultura de cada país, região ou organização. Nem sempre a posse material de um carro, ou uma mansão serão suficientes para demarcar a ostentação de um grupo, visto que, nem todos os grupos formaram suas relações de dominação pela posse desses artefatos, talvez os conhecimentos, os títulos, o tempo de casa, contém como formas de distinguir aqueles hierarquicamente superiores, ou aqueles que devem receber a atenção dos demais.

O texto "Liderança em uma Organização Pública Brasileira: Relações de poder e impactos das redes informais sobre as lideranças formais" (ALMEIDA et al 2014) mostra a relação entre lideranças formais e informais, e o efeito da primeira sobre as diretrizes da organização. Sua pesquisa indica um perfil de líder informal composto de competências técnicas, capacidade de formar opinião e carisma. 
$\mathrm{O}$ artigo também salienta que a liderança informal consegue, com maior facilidade, o engajamento de todos os funcionários em prol de um objetivo comum a atingir com maior grau de acurácia a eficiência naquilo que lhes são propostos. Esse artigo ajuda a pensar que o líder informal também poderia ostentar? Talvez não uma sala, um automóvel ou uma vaga especial, mas amizades? Habilidades de convencimento, bom desempenho interpessoal? Seria leviano dizer que não prontamente. Crê-se que sim, na medida em que certas amizades, podem em determinados ambientes serem mais importantes que a própria riqueza.

Esse capítulo trouxe uma recapitulação sobre as palavras-chave utilizadas para o levantamento dos artigos que trouxeram primeiros indícios sobre a ostentação para além do funk. O próximo capítulo se dedica a aprofundar as relações aqui evidenciadas culminando na cunhagem de um conceito explicativo para a ostentação.

\section{ANÁlise dos RESUltados}

Com base no levantamento de artigos relacionados ao tema ostentação, foi possível encontrar diversos artigos que puderam contribuir para a construção do termo ostentação, não de modo óbvio, mas a partir de um arranjo de conceitos que formaram uma trama conforme demonstrado na Figura 1. Ela representa as ideias chave utilizadas para a significação do termo ostentação a partir das áreas da Administração, da Comunicação Social, da Engenharia de Produção, das Ciências Sociais e do Turismo .

O conceito de poder simbólico encontrado na área de Ciências Sociais (BOURDIEU, 1998) é a base para entender que o poder não é um constructo imutável, mas subjetivo, na verdade, dependendo de relações entre indivíduos para a sua caracterização. É na relação que este poder simbólico se manifesta, criando as composições sociais; para uns, bastará o poder de ser chefe de família, para outros, o poder político é ideal, ou até mesmo religioso, para outros. É nessa modulação que os indivíduos vão encontrando seu lugar na sociedade.

O poder simbólico é relacional, alguns creditaram para outro a responsabilidade pelo grupo porque acreditaram que aquele é o melhor líder dentre todos. A cultura toma parte importante nesse 
processo, exemplifica-se isso, por exemplo, em instituições religiosas cujo sacerdócio pode ser exercido apenas por homens, ou por pessoas de uma determinada casta. O poder simbólico, coaduna com a crença estabelecendo as relações simbólicas pelas quais as pessoas se guiam.

Essas relações de poder são fundamentais dentro das organizações. Nelas, redes informais e formais se complementam e geram um intenso fluxo de troca de informação, desejos e objetivos. Aqui está a microfísica, que nas palavras de Foucault (2007) consiste em uma complexa rede de sentidos e forças variadas. "Os poderes se exercem em níveis variados e em pontos diferentes da rede social e neste complexo os micro-poderes existem integrados ou não ao Estado" (FOUCAULT, 2007, p. 7).

Turner (1987), conforme citado por Ferreira et al (2010), mostra em seus estudos dedicados à administração hospitalar que o hospital não é só uma instituição de extrema importância nos sistemas de saúde modernos, mas simboliza também o poder social da profissão médica, representando a institucionalização dos conhecimentos médicos especializados. Para tanto, talvez o termo ostentação, quando compreendido a partir do termo poder, pode significar uma determinada profissão, o local de moradia, carros, roupas, símbolos locais ou mesmo sobrenomes, haja vista que todos estes são artefatos que foram apropriados pelos indivíduos a fim de lhes render prestígio e autossatisfação.

Entende-se que o poder por si não basta, ele carrega consigo um aspecto de satisfação, ou seja, aquele em posição de poder goza das benesses dessa posição e por isso encontra-se em situação de evidência, regozijando-se pelo carinho, presentes, atenção, posição e outras tantas possibilidades de ganho. No entanto, exercer um cargo ou função sem reconhecimento não satisfaz o indivívuo na mesma medida. É preciso que haja um coletivo que sustente essa liderança, que acredite que ela realmente seja importante para a vida daquela comunidade ou organização.

Não há músico sem consumo, não há padre sem paróquia, não há chefe sem setor, é sempre o coletivo que justifica a ascenção de um sujeito. Nas organizações pode haver uma indicação que não seja aquela agradável a todos, no entanto as redes informais não 
estão alheias a isso. A liderança informal, nesses casos, surge como uma força contrária que pode causar diversos problemas para a organização.

Na obra Vigiar e Punir de Foucault (2014), as noções de espaço e geografia são centrais, uma vez que o que caracteriza o poder é a maneira como sua complexidade interna está associada às intervenções que se dão no lugar e no espaço (FERREIRA et al, 2010). Aqui, encontra-se a possibilidade de imaginarmos as salas, as vagas em garagem, as obras de arte, os locais onde pessoas moram. Todos esses, são espaços criados e apropriados por indivíduos, muitos deles usados no funk ostentação como sinônimos de prestígio. Portanto, tanto o espaço organizacional como o espaço social dos indivíduos poderiam ser vistos como ambientes pelo qual o sujeito se evidencia, e, em última análise, se compromete a atingir aos objetivos de lucro das organizações.

O funk ostentação mostra que pode haver uma relação da vontade de possuir e o ambiente de trabalho quando o sucesso e a possibilidade de consumir são fruto dos ganhos que o trabalho traz, além disso, a busca pelo título, pelas promoções, por prêmios de melhor funcionário são possíveis indicadores da presença da categoria ostentação no ambiente de trabalho e no dia a dia dos indivíduos, de modo muito sucinto, não seria o estilo musical que produz a vontade de ter, mas seria o oposto.

O estilo musical é, em si, outro artefato carregado de símbolos. Ele é fruto do desejo pelo consumo crescente das classes C, D e E, no entanto não é restrito a elas. Bourdieu (1998) em sua obra, analisa os padrões de consumo da burguesia francesa de sua época, justamente evidenciando o desejo pelo refinado, pelas artes dos grandes mestres, a educação erudita. Naquele contexto ostentar significa obter capital social por meio do capital cultural.

No entanto, os tempos são outros, as relações, portanto, também são outras. Em uma época em que a internet se espalha por diversos locais, ostentação pode significar um conjunto de belas fotos em determinada rede social, a possibilidade de ser ouvido por milhares de pessoas por meio de um streaming de jogos, maquiagens, viagens, etc? A internet possibilitou a criadores de conteúdos surgirem sem a ajuda de antigos meios de comunicação, tornando-os lideranças 
carismáticas pelo mérito de seus próprios canais. Surge então a profissão de influenciador digital.

Fischer (1994, p. 85), em sua obra denota a existência de "demarcadores" com "função preventiva, indicando aos outros quem possui e ocupa o espaço assim delimitado". Essas demarcações podem também refletir e traduzir a posição ocupada por indivíduos na organização: as dimensões da sala ocupada, o andar ou local, o modelo da cadeira, as dimensões (e estilo) da mesa; enfim, esses elementos estão impregnados de simbolismos de mensagens intraambientais. (Ver Figura 1).

A distribuição dos artefatosnum espaço e a arrumação desse são uma expressão do sistema hierárquico e uma de suas formas mais visíveis, dá-se a isso o nome de geografias do poder, segundo Foucalt (2007) .

É preciso fazer uma abstração nesse momento, incluindo os espaços digitais na discução de marcadores. Não são apenas os espaços físicos ou as características objetivas que determinam o local de um sujeito no grupo. Há artefatos diáfanos, quase imperceptíveis que possibilitam a ascenção ou queda de sujeitos em uma hierarquia social.

Por isso, é preciso conceber que tanto estruturas de poder quanto a ostentação não são comumente percebidas pelas pessoas que estão envolvidas com ela, seja no ambiente de trabalho, seja em outros campos da sociedade. A ostentação se camufla em ideias como a melhora de vida e a busca pelo conforto familiar. Assim como o poder que se camufla, a ideia de troca, prestígio e lucro individualizado também. De acordo com Matos et al (2010), a definição de Foucault (1985) de como o poder mascara uma parte importante de si, deixa evidente a camuflagem espontânea do poder e ainda que é ali mesmo que está seu sucesso, na proporção daquilo que consegue ocultar.

Não há porque ostentar se não houver a contraparte da admiração, aqui há uma dualidade admirado-admirador. Sem um admirador não há por que querer admiração, a ostentação parece depender do outro, esse outro precisa encontrar e entender o valor daquilo que se ostenta, do contrário o efeito do prestígio não se realiza. Portanto, seria possível inferir que a ostentação é sempre relacio- 


\section{FIGURA 1- Sistematização do referencial teórico}

\begin{tabular}{|c|c|c|c|c|c|c|}
\hline Titulo & Ano & Autor & Area & perlódico/evento & Termo Investlgado & Concel to chave \\
\hline $\begin{array}{l}\text { Religl ao e Poder: Os } \\
\text { simbolos do poder } \\
\text { sagrado. }\end{array}$ & 2008 & José Carlos Pere ira & Cénclas 5oclats & $\begin{array}{l}\text { Revista Ele tronica de } \\
\text { clennclas } 50 c 1 \text { ats }\end{array}$ & Poder 5 imb ólico & $\begin{array}{l}\text { O po der si mbolico, construl do a partir das } \\
\text { crnças indi ividuas col etadas a partir da } \\
\text { vive ncla em me lo a socled ade, costumese } \\
\text { conce it os comumente acei tos. }\end{array}$ \\
\hline $\begin{array}{l}\text { Re laç̧es de Po dere } \\
\text { Decisăo: Conflitos } \\
\text { entre médicose } \\
\text { administradores } \\
\text { hospitalares }\end{array}$ & 2010 & $\begin{array}{l}\text { LETICIA CORRËA MAGALHĀES } \\
\text { FERREIRA, FERNANDO } \\
\text { COUTINHO GARICIA E } \\
\text { ADRIANE VIEIRA }\end{array}$ & Admin Ist raç̧̧๐ & $\begin{array}{l}\text { Revista de } \\
\text { Admnistr açăo } \\
\text { Mackenzle }\end{array}$ & Rel a ques de poder & $\begin{array}{l}\text { Relações de poder deixa de ser visto } \\
\text { como conceito final em si, para } \\
\text { demonstrar que é um produto da } \\
\text { relação entre individuos. Dessas } \\
\text { relações nascem o produto final } \\
\text { denominado poder }\end{array}$ \\
\hline $\begin{array}{c}\text { Estudo Observacional } \\
\text { das Re laçBes de Poder } \\
\text { no filme: "O Óleo de } \\
\text { Lorenzo". }\end{array}$ & 2010 & $\begin{array}{l}\text { Fátima Regina Ney Matos, } \\
\text { Afonso Came iro U mae } \\
\text { Cláudia Marla Gl esbrecht }\end{array}$ & Admin Istraçăa & $\begin{array}{c}\text { Cadernos EBEP.COM } \\
\text { FOV }\end{array}$ & Relạ̧es de poder & $\begin{array}{l}\text { Nem todos os individous alcançarão o } \\
\text { poder que desejam, mas de modo } \\
\text { geral, sempre haverá um individuo ideal, } \\
\text { que galgou patamares maiores e por } \\
\text { isso tem para si parcela significativa de } \\
\text { poder e apreço. }\end{array}$ \\
\hline $\begin{array}{l}\text { Microflsica do poder } \\
\text { no turi smo: Reflex Bes } \\
\text { sobre as rel aç8 es de } \\
\text { poder no Consel ho } \\
\text { Est aud al de Turismo } \\
\text { do Rlo Grnde do Norte }\end{array}$ & 2011 & $\begin{array}{l}\text { Lore Fortes, Anna Karenina } \\
\text { Chaves Del gado e Darilyne } \\
\text { Fontes Virgllio }\end{array}$ & Turismo & $\begin{array}{l}\text { Cade mo virtual de } \\
\text { Turismo }\end{array}$ & Micrísica do poder & $\begin{array}{l}\text { lindividuos buscam deter poder, isso } \\
\text { porque o individuo inserido no contexto } \\
\text { social brasileiro, construido a partirda } \\
\text { cultura, e do colefivo de cidadãos não } \\
\text { está acostumado ao protagonismo, mas } \\
\text { a uma estrutura de mando e } \\
\text { subordinação que tem suas bases } \\
\text { ainda no periodo militar brasileiro. }\end{array}$ \\
\hline $\begin{array}{l}\text { A ARTE IMITA A VIDA? } \\
\text { CULTURA, VALORES, } \\
\text { PODER ELIDERANÇA } \\
\text { NAS ORGANIZAÇOEES }\end{array}$ & 2012 & $\begin{array}{l}\text { Elvis Sil ve ira-Martins, Deosir } \\
\text { Flávio Lobo de Castro Júni or e } \\
\text { Clarissa Ribelro-Martins }\end{array}$ & Admin istraç̧ొ & $\begin{array}{c}\text { Revista de } \\
\text { Admn istr açăo Faces }\end{array}$ & $\begin{array}{c}\text { Cultura } \\
\text { organizacional }\end{array}$ & $\begin{array}{c}\text { A cultura organizacionalé futo da } \\
\text { cultura nacional, ou local, e é a partir } \\
\text { dela que individuos procuram se orientar } \\
\text { e agir dentro de ambientes } \\
\text { organizacionais. }\end{array}$ \\
\hline $\begin{array}{l}\text { Ostentaçă o fora do } \\
\text { normal. Quem tem } \\
\text { motor faz amor, quem } \\
\text { năo tem passa mal": } \\
\text { Uma anallse so bre o } \\
\text { Funk da Ostentaçăo }\end{array}$ & 2013 & $\begin{array}{l}\text { Bárbara Marina Almelda dos } \\
\text { SANTOS e Shemilla Rossana } \\
\text { de Oliveira PAIVA }\end{array}$ & $\begin{array}{l}\text { Clênclas da } \\
\text { Comuni caçăo }\end{array}$ & $\begin{array}{l}\text { xv Congresso de } \\
\text { Clänclas da } \\
\text { Comuni caçăo na } \\
\text { Regla à No rde ste }\end{array}$ & Funk osten taç̧ว & $\begin{array}{l}\text { Apresentação da nova modalidade de } \\
\text { funok a partir de uma perspectiva da } \\
\text { área de comunicação social, sua } \\
\text { ligação } \infty \text { m o consumo, satisfação e a } \\
\text { perœepção social a partir dessa } \\
\text { capacidade de consumir. }\end{array}$ \\
\hline
\end{tabular}

Fonte: Os autores. 
nal. Ostentar pode significar atender, em verdade, aos anseios dos outros. Pode se corroborar para a existência de valores simbólicos diferentes atribuídos a cada tipo de trabalho, que tem seu grau de valor simbólico e uma determinada capacidade de prover admiração.

A partir da relação feita entre os termos poder simbólico, relações de poder, funk ostentação, consumo e organizações presente nos textos selecionados para análise, pode-se inferir que a categoria ostentação tem como significado: o comportamento consciente ou não de tomar algo para si que tenha significado, a partir da vivência e da relação com o meio ao qual o sujeito está inserido, de forma que este algo possa ser mostrado (torna-se ostensivo), em sua corporeidade ou externalidade, a fim de que outro lhe valorize ou empodere, ampliando assim sua participação social e seu bem-estar consigo mesmo.

Essa definição corrobora com os conceitos trazidos em cada um dos artigos levantados. A ostentação, portanto faz parte do processo de exercer poder. Ela é o efeito relacional entre os sujeitos e seus líderes, ela garante o reconhecimento desse por aqueles como força legitimadora das posições. É conformadora na medida em que enquandra a todos dentro de um padrão de consumo e comportamentos, relacionando-se ao habitus de Bourdieu (1998).

Perceba, o estetoscópio (artefato material) define o médico, que o coloca sobre os ombros enquanto caminha pelo hospital. Embora existam diversas outras profissões em um hospital, sabe-se quem é médico pelo artefato singular. O médico carrega consigo o estetoscópio, que por sua vez carrega o peso da profissão e toda a contrução daqueles que, imersos nessa cultura específica, se relacionam com o profissional.

Assim são os professores com seus jalecos, os executivos com seus ternos, os juízes com suas togas. São os estímulos sensoriais daqueles e daquelas que estão à volta que determinam a importância dos sujeitos. No entanto, para os que estão em volta, o traço distintivo justifica a admiração. Esse é o papel da ostentação, determinar quem ocupa cada local no jogo dos espaços sociais. 


\section{CONSIDERAÇões FINAIS}

Pode-se dizer que embora o termo ostentação esteja sendo usado recentemente, seu uso na língua portuguesa é antigo, sorvendo de temas muito próximos, como poder, cultura e relações interpessoais. Atualmente, com o surgimento do funk ostentação, o momento cultural no qual vivem os jovens brasileiros atribui a ostentação o sentido de possuir e mostrar bens materiais. Em outros países, a ostentação pode ser tratada com outras nomenclaturas, visto que o funk ostentação é uma manifestação particularmente brasileira.

Como objetivo este trabalho buscou significar a palavra ostentação próxima a categoria teórica de 'poder' na área dos estudos organizacionais, buscando ampliar o que se entende por ostentação para além da cena do funk nacional. Considera-se que o objetivo foi atingido, já que foi possível relacionar a ostentação ao conceito de poder nas organizações, ainda que em um momento exploratório.

Como indicações para futuras pesquisas indica-se a investigação em periódicos internacionais, além disso a busca pode considerar uma ampliação no período de publicações (considerando anos anteriores a 2000 e posteriores a 2014). Considera-se também que buscas teórico-empíricas sobre a ostentação nos ambientes organizacionais são indispensáveis para ampliação e revisão do conceito aqui apresentado.

Este artigo é caracterizado como uma pesquisa exploratória a partir de dados secundários por meio de pesquisas do tipo bibliográfica e bibliométrica. Conforme Jung (2004, p. 160), o estudo bibliográfico objetiva "conhecer as diversas formas de contribuições científicas existentes que foram realizadas sobre determinado assunto ou fenômeno", ou, na afirmação de Vieira (2007), estudos sobre a produção a respeito de determinado tema podem contribuir para avanços na discussão científica.

A construção do conceito ostentação, foi possível por meio da combinação do que se chamou de conceitos chave encontrados em cada artigo selecionado, que por sua vez possibilitaram um diálogo entre os artigos, como um emaranhando que aos poucos compôs um sentido.

Pode-se dizer que o debate aqui trazido é apenas um primeiro entendimento da categoria ostentação. Ainda assim, o conceito 
cunhado por essa análise em que a ostentação é: o comportamento consciente ou não de tomar algo para si que tenha significado, a partir da vivência e da relação com o meio ao qual o sujeito está inserido, de forma que este algo possa ser mostrado (torna-se ostensivo), em sua corporeidade ou externalidade, a fim de que outro lhe valorize ou empodere, ampliando assim sua participação social e seu bem-estar consigo mesmo, tem profundas relações com os termos relações de poder e poder simbólico, ambos amplamente tratados pela teoria organizacional, possibilita uma sistematização capaz de fomentar o debate acadêmico sobre a temática. A materialização de um conceito incentiva a busca por explicações cada vez mais complexas.

Por fim, salienta-se que a busca por este fenômeno de modo empírico nas organizações, por exemplo, analisando a relação entre liderança e ostentação, ou ainda se os estudos da ostentação poderiam produzir novas formas de bonificar carreiras. Como o termo ostentação é visto e principalmente encontrado no ambiente organizacional? Como o gosto e a ostentação estão relacionados e, se são termos que se complementam? Porque algumas profissões recebem mais status que outras? São estudos pertinentes de melhores aprofundamentos em áreas como marketing, estudos sociais, teoria das organizações e gestão de pessoas.

\section{REFERÊNCIAS}

AKTOUF, O. O simbolismo e a cultura de empresa: dos abusos conceituais às lições empíricas. In: CHANLAT, J. F. (Org.). O indivíduo nas organizações: dimensões esquecidas. São Paulo: Atlas, 1994. v. 2, p. 39-79.

ALMEIDA, R.; GUIMARÃES, L.; BATISTA, N. Liderança em uma organização pública brasileira: Relações de poder e impactos das redes informais sobre as lideranças formais. In: ENCONTRO DE ESTUDOS ORGANIZACIONAIS ANPAD, 8., 2014, Gramado. Anais... Gramado: Associação Nacional de Pós-graduação e Pesquisa em Administração, 2014.

BOURDIEU, P. A escola conservadora: as desigualdades frente à escola e à cultura. Escritos de Educação. Petrópolis: Vozes, p. 39-64, 1998.

CRUZ, C.; RIBEIRO, U. Metodologia científica: teoria e prática. Rio de Janeiro: Axcel Books, 2003.

DANTAS, S. S. et al. Jovens de Baixa Renda: Aspirações de Consumo e Funk Ostentação.

Revista da Faculdade de Administração e Economia, v. 9, n. 1, p. 191-213. 
DANTAS, G. A. Plaquê de 100. Disponível em: https://www.letras.mus.br/mc-guime/contando-os-plaques-de-100/. Acesso em 01 de fevereiro de 2018.

ENRIQUEZ , E. A organização em análise. Petrópolis: Vozes, 1997.

ESSINGER, S. Batidão: uma história do funk. Rio de Janeiro e São Paulo: Record, 2005.

FERREIRA, L.; GARCIA, F.; VIEIRA, A. Relações de poder e decisão: Conflitos entre médios e administradores hospitalares. Revista de Administração Mackenzie, São Paulo, v.11, n.6, p. 31-54, nov./dez. 2010.

FISCHER, G. N. Espaço, identidade e organização. In: CHANLAT, J.-F. (Coord.). O indivíduo na organização: dimensões esquecidas. São Paulo: Atlas, 1994.

FLEURY, M. T. O desvendar a cultura de uma organização. In: FLEURY, M. T.;

FISCHER, R. M. Cultura e Poder nas Organizações. São Paulo, Atlas, 1989.

FOUCAULT, M. Microfísica do poder. 24. ed. Rio de Janeiro: Graal, 2007.

FOUCAULT, Michel. Vigiar e punir. Leya, 2014.

GALBRAITH, J. K. O pensamento econômico em perspectiva: uma história crítica. São Paulo: Pioneira, 1989.

GONÇALVES, E. L. Estrutura organizacional do hospital moderno. Revista de Administração de Empresas, São Paulo, v. 38, n. 1, p. 80-90, jan./mar. 1998.

JUNG, C. F. Metodologia para pesquisa e desenvolvimento: aplicada a novas tecnologias, produtos e processos. Rio de Janeiro: Axcel Books, 2004.

MACIAS-CHAPULA, C. A. O papel da informetria e da cienciometria e sua perspectiva nacional e internacional. Ciência da Informação, v. 27, n. 2, p. 64-68, 1998.

MARTINS, E.; JÚNIOR, D.; RIBEIRO-MARTINS, C. A arte imita a vida? Cultura, Valores, Poder e Liderança nas Organizações. Revista de Administração Faces, Belo Horizonte, v.12, n.1, p.97-116,jan./mar. 2012.

MATOS, F.; LIMA, A.; GIESBRECHT, C. Estudo observacional das relações de poder no filme óleo de Lourenço. Cadernos EBAPE, Rio de Janeiro, v.9, n.2, p.438-449, jun. 2011.

MORGAN, G. Imagens da Organização. São Paulo: Atlas, 1996.

NARDI, S. A nova era do consumo de baixa renda: consumidor, mercados, tendências

e crise mundial. São Paulo: Novo Século, 2009.

OLIVEIRA, W.; GARCIA, F. Poder e trabalho: Prazer e ou sofrimento?. Revista de Administração Faces, Belo Horizonte, v.2, n.4, p.131-148 out./dez. 2011.

OSTENTAÇÃO. Dicionário online Michaelis, 24, Jan. 2018. Disponível em <http://michaelis. uol.com.br/moderno-portugues/busca/portugues brasileiro/ostentação\%C3\% A7\% C3\%A3o/ >. Acesso em 24 jan. 2018.

PABST, F. R..; SIQUEIRA, M. V. S. Discurso organizacional como manifestação de poder: 
um estudo com executivos de empresas modernas. RBGN: Revista Brasileira de Gestão de Negócios, v. 10, n. 29, p. 376-390, 2008.

PEREIRA, J. Religião e poder: Os símbolos do poder sagrado. Revista Eletrônica de Ciências Sociais, Juiz de Fora, MG, ano 2, v.3, 2008. Disponível em: <https://csonline.ufjf.emnuvens. com.br/csonline/article/view/366/339>. Acesso em 10 nov. 2015.

SANTOS, B.; PAIVA, S. Ostentação fora do normal. Quem tem motor faz amor, quem não tem passa mal: Uma análise sobre o funk da ostentação. CONGRESSO BRASILEIRO DE CIENCIAS DA COMUNICAÇÃO, 15., 2013, Mossoró. Anais... Mossoró: Sociedade Brasileira de Estudos Interdisciplinares da comunicação, 2013.

SCHEIN, E. On dialogue, culture and organizational learning. REFLECTIONS, Organizational Dynamics, São Paulo, v. 4, n.4, p. 27-37, sumer. 1993.

SCHEIN, E. Organizational Culture and Leadership. 2. ed. San Francisco: Jossey-Bass Publishers, 1992.

UNG, C. F. Metodologia para pesquisa e desenvolvimento: aplicada a novas tecnologias, produtos e processos. Rio de Janeiro: Axcel Books, 2004.

VERGARA, S. C; PINTO, M. C. S. Nacionalidade das referências teóricas em análise organizacional: um estudo das nacionalidades dos autores referenciais na literatura brasileira. In: ENCONTRO DE ESTUDOS ORGANIZACIONAIS, 1, Curitiba, PR. Anais... 2000.

VIEIRA, A. M. Cultura organizacional em instituições de ensino: mapeamento e análise descritivo-interpretativa da produção acadêmica (1990-2005). 2007. 237f. Tese (Doutorado em Educação) - Universidade Estadual Paulista (UNESP), Marília, 2007.

VIRGINIO, D. F; DELGADO, A. K. C; FORTES, L. Microfísica do poder no turismo: reflexões sobre as relações de poder no Conselho Estadual de Turismo do Rio Grande do Norte. Caderno Virtual de Turismo. Rio de Janeiro, v. 11, n. 2., p.267-281, ago. 2011.

ZAPPANI, A.; et all. Relações de poder: Uma abordagem voltada à cultura organizacional. Revista de Administração, Contabilidade e Contabilidade, Joaçaba V.8, n.2, p. 239-266, jun./dez. 2009.

Recebido em: 28-8-2018

Aprovado em: 9-5-2019

Avaliado pelo sistema double blind review.

Editor: Coordenação do PPGA/UMESP

Disponível em http://mjs.metodista.br/index.php/roc 